\title{
REMOVAL OF HEAVY METALS USING ION-BINDING COPOLYMER INVOLVING PTHALLIC ACID WITH FORMALDEHYDE BY BATCH EQUILIBRIUM TECHNIQUE
}

\author{
${ }^{1}$ Gurnule W.B. and ${ }^{2}$ Khobragade J.V. \\ ${ }^{1}$ Kamla Nehru mahavidyalaya, Nagpur (M.S) India \\ ${ }^{2} \mathrm{G}$. N. College, Ballapur, Chandrapur (M.S) India \\ Email: wbgurnule@gmail.com
}

\begin{abstract}
Pthallic acid - melamine - formaldehyde copolymer resin was synthesized through the condensation of pthallic acid and melamine with formaldehyde in the presence of hydrochloric acid as a catalyst and with various molar ratios of the reacting monomers. The resulting copolymer was characterized with UV-visible, FTIR, ${ }^{1} \mathrm{H}-\mathrm{NMR}$ and $\mathrm{C}^{13}$ NMR spectral data, employed to determine the reactivity of monomers. The average molecular weight of this resin was determined with conductometric titration in a non-aqueous medium. The chelating ion-exchange properties were also studied with the batch equilibrium method. The chelating ion-exchange properties of this copolymer was studied for seven $\mathrm{Cu}^{2+}, \mathrm{Ni}^{2+}, \mathrm{Cd}^{2+}, \mathrm{Co}^{2+}, \mathrm{Hg}^{2+}, \mathrm{Zn}^{2+}, \mathrm{Pb}^{2+}$ and $\mathrm{Fe}^{3+}$ metal ions. The study was carried out over a wide $\mathrm{pH}$ range and in media of various ionic strengths. The copolymer showed a higher selectivity for $\mathrm{Fe}^{3+}$ ions than for $\mathrm{Cu}^{2+}, \mathrm{Ni}^{2+}, \mathrm{Cd}^{2+}, \mathrm{Zn}^{2+}, \mathrm{Hg}^{2+}$ and $\mathrm{Pb}^{2+}$. The difference in the selectivity of order of metal ions may be due to the particle size, high porosity nature, large surface area, nature of the material and metal ions. The surface morphology of the copolymer resin was examined by scanning electron microscopy and it establishes the transition state between crystalline and amorphous phase.
\end{abstract}

Keywords: Copolymer, Morphology, Ion-exchange, Resin, Polycondensation, Batch equilibrium

\section{Introduction:}

Water plays a great role in our body system. Various contaminants are released to the wastewater with the rapid industrialization of human society, including heavy metal ions, which are seriously harmful to human health. Among all water contaminations, heavy metal ions such as $\mathrm{Pb}^{2+}, \mathrm{Fe}^{3+}, \mathrm{Co}^{2+}$, $\mathrm{Cd}^{2+}, \mathrm{Zn}^{2+}, \mathrm{Hg}^{2+}, \mathrm{Ni}^{2+}$ and $\mathrm{Cu}^{2+}$ have high toxic properties which can cause severe health problems in animals and human beings. It is well known that chronic cadmium toxicity is the inducement of Japan Itai-Itai disease. The harmful effects of $\mathrm{Cd}^{2+}$ also lead to a number of acute and chronic disorders, such as renal damage, emphysema, hypertension, testicular atrophy, skeletal malformation, anaemia, and liver, kidney and brain damages.Several techniques have been developed for the qualitative and quantitative determination of such metal ions by ion exchange, solvent extraction, reverse osmosis, adsorption, complexation and precipitation. Ionexchange process has been used in the recent years for the application in waste water treatment, identification and removal of heavy metal ions [1-5].
The chelating ion-exchange properties of copolymer resin derived from $o$-aminophenol and urea with formaldehyde were studied. The synthesized copolymer acts as an effective cation exchanger for trivalent and divalent heavy metal ions such as $\mathrm{Fe}^{3+}$, $\mathrm{Cd}^{2+}, \mathrm{Cu}^{2+}, \mathrm{Zn}^{2+}$ and $\mathrm{Pb}^{2+}$ ions. From the results, the copolymer showed higher selectivity of metal ion for $\mathrm{Fe}^{3+}, \mathrm{Cd}^{2+}$ and $\mathrm{Co}^{2+}$ than $\mathrm{Cu}^{2+}, \mathrm{Hg}^{2+}, \mathrm{Zn}^{2+}, \mathrm{Ni}^{2+}$ and $\mathrm{Pb}^{2+}$ ions. Anthranilic acid and salicylic acid with formaldehyde were prepared by polycondensation method in glacial acetic acid medium. Copolymer was involved as an ion-exchanger for different transition heavy metal ions. The order of removal of metal ion was found to be $\mathrm{Pb}^{2+}>\mathrm{Zn}^{2+}>\mathrm{Cu}^{2+}>$ $\mathrm{Mg}^{2+}>\mathrm{Ba}^{2+}[6]$.

The study was done between the commercial activated carbon, chitosan and chitosan/activated carbon composite for the removal of cadmium ions from aqueous solution. The $\mathrm{pH}$ solution of adsorbent is the most important factor for the removal of heavy metal ions [7]. Chitosan/charcoal composite was prepared by chitosan and charcoal via a simple solution-evaporation method. The prepared composite can effectively used for the treatment of 
chromium from waste water. The composite was employed for the adsorption of chromium by various rates,

$\mathrm{pH}$ and dose of adsorbent. The adsorption capacity was dependent on maximum $\mathrm{pH}$ [8].

Based on the literature, we have concluded that there were no earlier reports for the copolymer resin. Hence, a novel copolymer was synthesized from pthallic acid and melamine with formaldehyde. Batch separation method was adopted and reported for the removal of heavy metal ionsusing the copolymer resin. The ionexchange studies of copolymer resin have been studied. The results were compared with theearlier literatures and commercially available resins.

\section{Experimental:}

\section{Material and Methods}

The important chemicals (starting materials) such as pthallic acid, melamine and formaldehyde used in the preparation of new PAMF copolymer resin were of chemically pure grade and, wherever necessary, the purity was tested and confirmed by thin layer chromatography.

\section{Synthesis of PAMF copolymer resin}

The PAMF copolymer resin was prepared by the condensation polymerization of pthallic acid $(0.2 \mathrm{~mol})$ and biuret $(0.1 \mathrm{~mol})$ with formaldehyde $(0.4 \mathrm{~mol})$ in acidic hydrochloric acid medium at $126 \pm 2{ }^{\circ} \mathrm{C}$ in an oil bath for $5 \mathrm{hrs}$. The solid product obtained was immediately removed from the flask as soon as the reaction period was over. It was washed with cold water, dried and powdered. The powder was repeatedly washed with hot water to remove excess of pthallic acid - formaldehyde copolymer, which might be present along with the PAMF copolymer. The dried resin was further purified by dissolving in $8 \% \mathrm{NaOH}$ and regenerated in $1: 1(\mathrm{v} / \mathrm{v}) \mathrm{HCl} /$ water. The purified copolymer resin was finally ground well to pass through a 300 mesh size sieve and kept in vacuum over silica gel. The yields of these copolymer resins were found to be $82 \%$ and the melting point is between 445 - 454K. The sieved resin was used for further characterization.

\section{Characterization of PAMF copolymer resin}

The copolymer resin was subject to micro analysis for $\mathrm{C}, \mathrm{H}$ and $\mathrm{N}$ on an Elementary Vario EL III Carlo Erba 1108 elemental analyzer. The number average molecular weight $\bar{M} n$ was determined by conductometric titration in DMSO medium using ethanolic $\mathrm{KOH}$ as the titrant by using $25 \mathrm{mg}$ of sample. A plot of the specific conductance versus the milliequivalents of potassium hydroxide required for neutralization of $100 \mathrm{gm}$ of copolymer was made. Inspection of such a plot revealed that there were many discontinuities in the plot. From this plot, the first break and the last break were noted. The calculation of $\overline{M n}$ by this method is based on the following considerations [9] : (1) the first break corresponds to the stage at which the first acidic phenolic hydroxyl group is neutralized, and (2) the last break observed beyond the first break represents the stage at which phenolic hydroxyl group of all the repeating units are neutralized.On the basis of the average degree of polymerization, $\overline{(D P)}$ the average molecular weight has to be determined by following eq. (1)...

$\overline{\mathrm{DP}}$ $=\frac{\text { (Total milliequivalents of base required for complete neutralization) }}{\text { (Milliequivalents of base required for smallest interval) }}$

$\overline{\mathrm{Mn}}=\overline{\mathrm{DP}} \times$ molecular weight of the repeating unit

The intrinsic viscosity was determined using a Tuan-Fuoss viscometer [10] at six different concentrations ranging from $0.3 \mathrm{wt} \%$ to $0.05 \mathrm{wt} \%$ of resin in DMSO at $30^{\circ} \mathrm{C}$. Intrinsic viscosity (n) was calculated by the Huggin's eq.(2) [11] and Kraemer's eq.(3) [12].

In $\eta \mathrm{sp} / \mathrm{C}=[\eta]+\mathrm{K}_{1 .} \cdot[\eta]^{2} \cdot \mathrm{C}$

In $\eta$ rel $/ C=[\eta]-K_{2 .}[\eta]^{2} . C$

\section{Spectral Analysis}

The UV-Visible studies were out carried using Shimadzu UV-1800 Spectrophotometer in the range 200-800 $\mathrm{nm}$. The Infrared spectrum was recorded in the region of $500-4000 \mathrm{~cm}^{-1}$ on Shimadzu IR-Affinity Spectrophotometer at Department of Chemistry, Kamla Nehru Mahavidyalaya, Nagpur. ${ }^{1} \mathrm{H}-\mathrm{NMR}$ spectrum 
recorded by using BrukerAvance-II FT-NMR Spectrometer in DMSO-d6 solvent at STIC Analysis, Kochi. All the analytical and spectral studies for the newly synthesized copolymer were carried out at STIC Analysis centre, Kochi.

Surface analysis was performed using a scanning electron microscope (SEM), JEOL JSM-6380A Analytical Scanning Electron Microscope at VNIT, Nagpur, at various magnifications.

\section{Ion-exchange properties}

The ion-exchange properties of the PTMF copolymer resin was determined by the batch equilibrium method. We studied the influence of various electrolytes, the rate of metal uptake and distribution of metal ions between the copolymer and solutions.

Determination of metal uptake in the presence of electrolytes of different concentrations

The copolymer sample (25 mg) was suspended in an electrolyte solution $(25 \mathrm{ml})$ of known concentration. The $\mathrm{pH}$ of the suspension was adjusted to the required value by using either $0.1 \mathrm{~N} \mathrm{HCl}$ or $0.1 \mathrm{~N}$ $\mathrm{NaOH}$. The suspension was stirred for a period of $24 \mathrm{hrs}$ at $25^{\circ} \mathrm{C} .2 \mathrm{ml}$ of a $0.1 \mathrm{M}$ solution of metal ion was added to this suspension and the $\mathrm{pH}$ was adjusted to the required value. The mixture was again stirred at $25^{\circ} \mathrm{C}$ for $24 \mathrm{hrs}$ and filtered [13]. The solid was washed and the filtrate and washings were combined and the metal ion content was determined by titration against standard EDTA. The amount of metal ion uptake of the polymer was calculated from the difference between a blank experiment without polymer and the reading in the actual experiments [14]. The experiment was repeated in the presence of other three electrolytes such as $\mathrm{NaCl}, \mathrm{NaClO}_{4}$ and $\mathrm{Na}_{2} \mathrm{SO}_{4}$.

\section{Evaluation of the rate of metal uptake}

In order to estimate the time required to reach the state of equilibrium under the given experimental conditions, a series of experiments of the type describe above were carried out, in which the metal ion taken up by the chelating resin was determined from time to time at $25^{\circ} \mathrm{C}$ (in the presence of 25 $\mathrm{ml}$ of $1 \mathrm{M} \mathrm{NaNO}_{3}$ solution). It was assumed that, under the given conditions, the state of equilibrium was established within $24 \mathrm{hrs}$. The rate of metal uptake is expressed as a percentage of the amount of metal ions taken up at the state of equilibrium.

\section{Evaluation of the Distribution of Metal Ions at Different $\mathbf{p H}$}

The distribution of each one of the seven metal ions i.e. $\mathrm{Fe}^{2+}, \mathrm{Cu}^{2+}, \mathrm{Ni}^{2+}, \mathrm{Co}^{2+}, \mathrm{Zn}^{2+}$, $\mathrm{Cd}^{2+}$ and $\mathrm{Pb}^{2+}$ in the polymer phase and the aqueous phase was determined at $25^{\circ} \mathrm{C}$ and in the presence of a $1 \mathrm{M} \quad \mathrm{NaNO}_{3}$ solution. The experiments were carried out as described earlier at different $\mathrm{pH}$ values. The distribution ratio " $\mathrm{D}$ " is defined by the following relationship: $D$

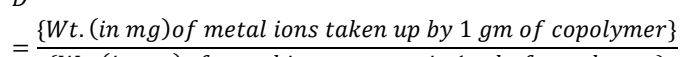

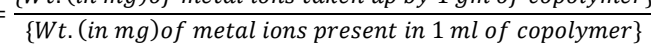

\section{Results and discussion:}

The resin sample was cream in color, insoluble in commonly used organic solvents, but was soluble in dimethyl formamide, dimethyl sulphoxide, tetrahydrofuran, pyridine and concentrated $\mathrm{H}_{2} \mathrm{SO}_{4}$. The synthesized resins do not show sharp melting point but undergo decomposition between 445-454 K. Based on the analytical data, the empirical formula of the copolymer resin is found to be $\mathrm{C}_{23} \mathrm{H}_{19} \mathrm{O}_{8} \mathrm{~N}_{6}$, which is in good agreement with the calculated values of $\mathrm{C}, \mathrm{H}, \mathrm{N}$ and $\mathrm{O}$. The resin was analyzed for carbon, hydrogen, and nitrogen content $\mathrm{C}=54.02 \%$ (Cal) and $54.44 \%(\mathrm{~F}) ; \mathrm{H}=3.75 \%(\mathrm{Cal})$ and $3.98 \%(\mathrm{~F}) ; \mathrm{N}=16.57 \%(\mathrm{Cal})$ and $16.82 \%(\mathrm{~F})$.

Number average molecular weights $(\overline{M n})$ of these copolymers have been determined by conductometric titration method in non-aqueous medium and using standard potassium hydroxide $(0.5 \mathrm{~N})$ in absolute ethanol as a titrant. The specific conductance was plotted against milliequivalents of ethanolic $\mathrm{KOH}$ required for neutralization of $100 \mathrm{gm}$ of each copolymer. There are several breaks before the complete neutralization of all phenolic hydroxyl groups. The first break in the plot was the smallest break and assumed that this corresponds to a stage in titration when an average one phenolic hydroxide group of each chain was neutralized. The average degree of polymerization $(\overline{D P})$ and hence the 
number average molecular weight $(\overline{M n})$ of all copolymer resins have been determined using the formula:

$(\overline{D P})=\frac{(\text { Total milliequivalents of base required for complete neutrilization }}{\text { Milliequivalents of base required for smallest interval }}$

\section{$(\overline{M n})=\overline{D P} \times$ Repeat unit weight}

The number average molecular weight could be obtained by multiplying $\overline{D P}$ by the formula weight of the repeating unit, i.e3894 [15]. Viscometric measurement was carried out in DMSO at $30^{\circ} \mathrm{C}$. The intrinsic viscosity was determined by the Huggin's eq. (2) and Kraemer's, eq. (3) which is 0.070. In accordance with the above relations, the plot of $\eta \mathrm{sp} / \mathrm{C}$ and $\eta \mathrm{rel} / \mathrm{C}$ versus $\mathrm{C}$ was linear giving slopes $K_{1}$ and $K_{2}$ (0.53) respectively. The intercept on the axis of viscosity function gave the (n) value in both the plots [16]. The values of (n) obtained from both relations were in good agreement with each other.

The UV-visible spectrum of PTMF copolymer resin is shown in Figure 1. UVvisible spectrum of PTMF resin has been recorded in pure DMSO in the wavelength range of $200-800 \mathrm{~nm}$ at a scanning rate of $100 \mathrm{~nm} \mathrm{~min}^{-1}$. The spectra of these copolymers exhibit two absorption maxima in the region of $280 \mathrm{~nm}$ and $320 \mathrm{~nm}$. These observed positions of the absorption bands indicate the presence of carbonyl group (ketonic) processing double bond, which is in conjugation with the aromatic nucleus [17]. The appearance of former band (more intense) can be accounted for $\Pi \rightarrow \Pi^{*}$ transition while the later band (less intense) may be due to $n \rightarrow \pi^{*}$ electronic transition. The shift from the basic value (viz. $240 \mathrm{~nm}$ and $310 \mathrm{~nm}$ respectively) may be due to conjugation effect, and the presence of phenolic hydroxyl group (auxochromes) is responsible for hyper chromic effect i.e. $\Sigma_{\max }$ higher values.

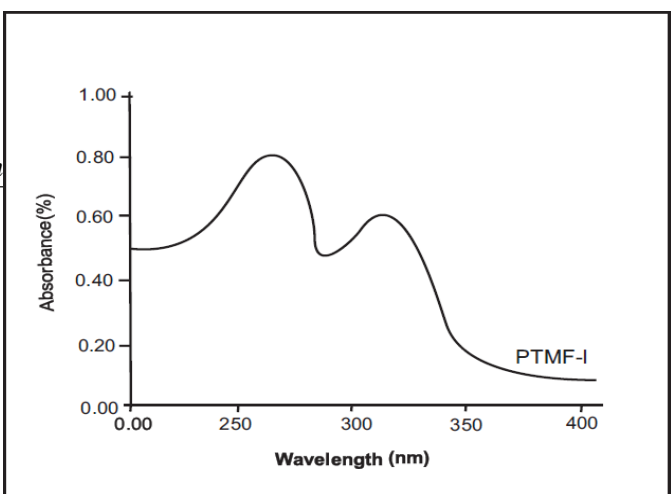

Fig.-1 UV-Visible spectra of PTMF-II copolymer

The FTIR spectra of copolymer resin is presented in Figure 2. The IR spectra revealed that the resin give rise to a broad band appearing in the region 3400-3800 $\mathrm{cm}^{-1}$ may be assigned to the stretching vibration of carboxylic acid groups exhibiting intermolecular hydrogen bonding [18]. The band at $3254 \mathrm{~cm}^{-1}$ assignable to $\mathrm{NH}-$ stretching, bending and deformation out of plane vibrations of melamine moiety in copolymers respectively. The band at $1502 \mathrm{~cm}^{-1}$ may be ascribed to aromatic skeletal ring [18]. The presence of methylene bridges $\left(-\mathrm{CH}_{2}-\right)$ in the polymeric chain may be assigned due to presence of band at $1460-1470 \mathrm{~cm}^{-1}, 1375-1360 \mathrm{~cm}^{-1}$ and 788 $753 \mathrm{~cm}^{-1}[18]$.

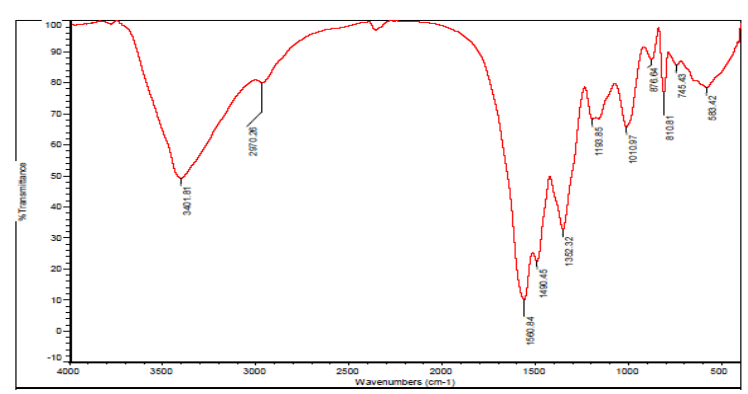

Fig.- 2. Infrared spectra of PTMF copolymer

Proton NMR spectra of copolymer resin is presented in Figure 3. Proton NMR spectra of copolymer resin show the intense signal arising in the region 7.80 (ס) ppm which may occur on account of hydroxyl proton of $\mathrm{COOH}$ group involved in the intermolecular hydrogen bonding[16]. The sharp intense peak at 6.80 ( $\delta$ ) ppm may be assigned to 
aromatic proton. A weak signal made its appearance at 3.90 (ठ) $\mathrm{ppm}$ which may be due to amido protons of - $\mathrm{NH}$ bridge in the chain [17]. An intense signal appearing at 2.60 (ठ) ppm may be due to methylene proton (- $\left.\mathrm{CH}_{2}-\right)$. Copolymer show signal around 3.62 (ठ) ppm suggesting the presence of methylene bridges of $\mathrm{Ar}-\mathrm{CH}_{2}-\mathrm{N}$ linkage [17]

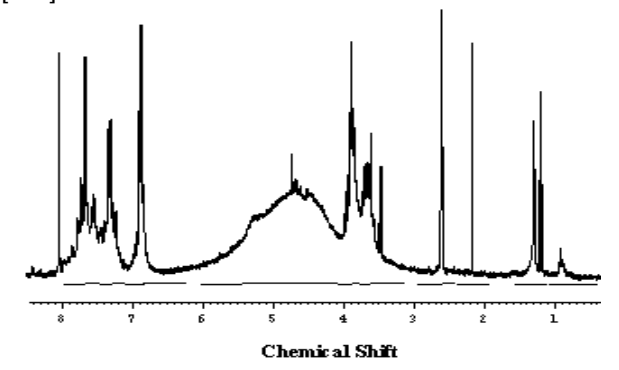

Fig.-3. Proton NMR spectra of PTMF polymer

The SEM photographs obtained in different magnifications for the PTMF copolymer resin are shown in Figure 4. It indicates that the PTMF copolymer has a net-like appearance and the surface features of the copolymer shows a fringed, scattered, and miscellaneous model of the crystallineamorphous structure. Scanning electron microscopy of copolymer was carried out to understand the inner morphology and pore structure. The morphology of fracture surfaces of the copolymer is quite different from that of polymer-metal complexes. It is clear from SEM that the copolymer is porous in nature. The morphology of the copolymer shows a fringed model of the semicrystalline nature. The fringes represent the transition between the crystalline and the amorphous phases. The copolymer exhibits a more amorphous character with a close-packed surface having deep pits and the reactivity of active sites buried in the copolymer matrix. The presence of few holes and cracks are noted which may be due to air voids[18].

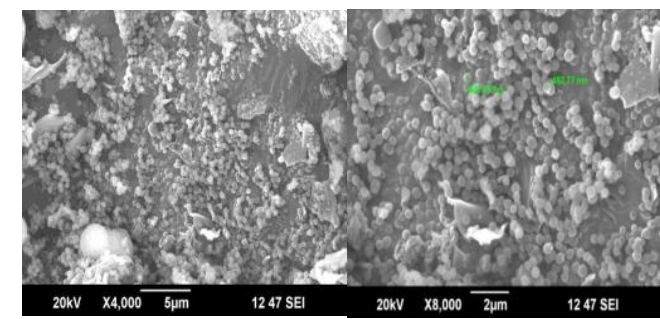

Fig.-4. Scanning Electron Microscopy Images of PTMF copolymer Resin

On the basis of the nature and reactive positions of the monomers, elemental analysis, electronic, IR, NMR spectra and molecular weight, the most probable structures have been proposed for copolymer resin.

\section{Ion-exchange properties}

With a view to ascertain the influence of various electrolytes on the selectivity of metal ions, the rate of metal uptake and the distribution ratio of metal ions between the copolymer and solution containing the metal ions, by using batch equilibrium method [19] was investigated. Data of experimental procedure for direct EDTA titration is presented in Table 1.

Table-1. Data of experimental procedure for direct EDTA titration

\begin{tabular}{|c|c|c|}
\hline $\begin{array}{l}\text { Metal ion } \\
\text { Colour change }\end{array}$ & Buffer used & Indicator used \\
\hline $\begin{array}{l}\text { Fe(III) } \\
\text { Blue-Yellow }\end{array}$ & Dil. $\mathrm{HNO}_{3} /$ dil. $\mathrm{NaOH}$ & Variamine blue \\
\hline $\begin{array}{l}\mathrm{Cu}(\mathrm{II}) \\
\text { black } \\
\text { Purple-Green }\end{array}$ & Dil. $\mathrm{HNO}_{3} /$ dil. $\mathrm{NaOH}$ & Fast sulphon \\
\hline $\begin{array}{l}\mathrm{Ni}(\mathrm{II}) \\
\text { Yellow-Violet }\end{array}$ & Aq. $\mathrm{NH}_{3} / \mathrm{NH}_{4} \mathrm{Cl}$ & Murexite \\
\hline $\begin{array}{l}Z n(I I) \\
\text { Wine Red-Blue }\end{array}$ & Aq. $\mathrm{NH}_{3} / \mathrm{NH}_{4} \mathrm{Cl}$ & Salochrom \\
\hline $\begin{array}{l}\text { Cd(II) } \\
\text { Red-Yellow }\end{array}$ & Hexamine & Xylenol orange \\
\hline $\begin{array}{l}\mathrm{Pb}(\mathrm{II}) \\
\text { Red-Yellow }\end{array}$ & Hexamine & Xylenol orange \\
\hline $\begin{array}{l}\text { Co(II) } \\
\text { Red-Yellow }\end{array}$ & Hexamine & Xylenol orange \\
\hline
\end{tabular}

The PTMF copolymer shows that the group $\mathrm{COOH}$ and $-\mathrm{NH}$ contain lone pair of electrons, which can be donated to the metal ion during complex formation. Hence it shows chelating behavior. When polymer is suspended in metal ion solution, the chelating tendency of copolymer forms the 
cyclic complex with the metal ion, which absorbs the metal ion from solution to surface of polymer. This mechanism of adsorption of metal ion by polymer ligands is known at metal uptake of polymer. Due to metal uptake concentration of metal ion in solution decreases, this can be determined by titration with standard EDTA solution. The metal uptake capacity of polymer is different for different metal ion, is also known as selectivity of polymer towards the uptake of metal ion. The metal uptake of copolymer depends on three variables, concentration of electrolyte solution, shaking time and $\mathrm{pH}$ of the solution. The chelating behavior of PTMF copolymer was studied with these three variables by keeping two variable constant at each time. Polymer + metal ion solution + shaking polymer - metal ion chelate

(Metal uptake capacity of polymer depends on stability of polymer - metal ion chelate)

Batch equilibrium technique developed by Gregor et al. and DeGeiso et al. was used to study of ion exchange property of PTMF copolymer resin. The result of the batch equilibrium study carried out with the copolymer resin PTMF is presented in Figure 5-10. eight metal ions $\mathrm{Fe}^{3+}, \mathrm{Cu}^{2+}, \mathrm{Ni}^{2+}, \mathrm{Zn}^{2+}$, $\mathrm{Cd}^{2+}, \mathrm{Co}^{2+}, \mathrm{Hg}^{2+}$ and $\mathrm{Pb}^{2+}$ in the form of aqueous metal nitrate solution were used. The ion exchange study was carried out using three experimental variables: (a) electrolyte and its ionic strength (b) shaking time and (c) $\mathrm{pH}$ of the aqueous medium. Among three variables, two were kept constant and only one was varied at a time to evaluable its effect on metal uptake capacity of the polymer [20].

\section{Effect of electrolytes and their concentration on the metal ion uptake capacity}

We examined the effect of $\mathrm{NO}_{3}{ }^{-}, \mathrm{Cl}^{-}, \mathrm{SO}_{4}{ }^{2-}$ and $\mathrm{ClO}_{4}^{-}$at various concentrations on the equilibrium of metal resin interaction of constant $\mathrm{pH}$. Different metal ions have different $\mathrm{pH}$ in solution, has been mentioned in [Fig.5-8], which shows that the amount of metal ions taken up by a given amount of copolymer depends on the nature of concentration of the electrolyte present in the solution. In the presence of nitrates, perchlorate and chloride ions the uptake of $\mathrm{Fe}^{3+}, \mathrm{Cu}^{2+}, \mathrm{Zn}^{2+}$ and $\mathrm{Pb}^{2+}$ ions increasing with increasing concentration of electrolytes. Whereas in presence of sulphate ions, the amount of above maintained ions taken up by the copolymer resin decreases with increasing concentration of the electrolyte [21 ]. Above $\mathrm{NO}_{3}^{-}, \mathrm{Cl}^{-}$, and $\mathrm{ClO}_{4}^{-}$ions form weak complex with the above metal ions, while $\mathrm{SO}_{4}{ }^{-2}$ form stronger complex thus the equilibrium is affected. This may be explained on the basis of the stability constants of the complexes with those metal ions and nature of ligands.

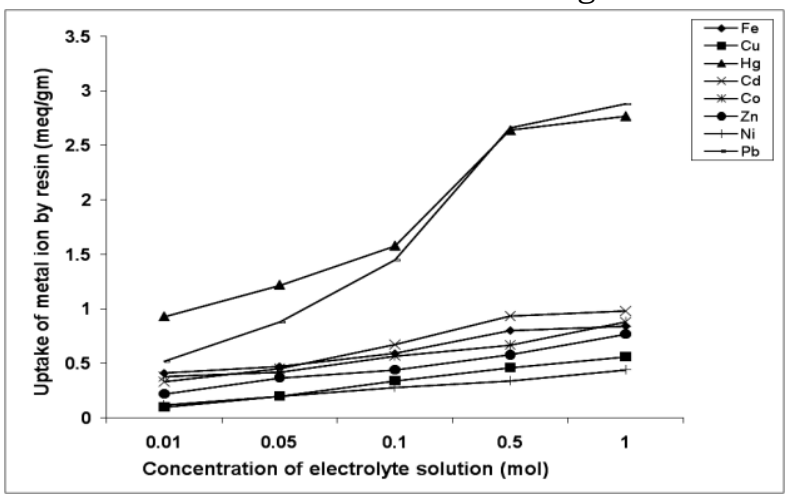

$\left.\mathrm{M}\left(\mathrm{NO}_{3}\right)_{2}\right]=0.1 \mathrm{Mol} / 1$; Volume = ml; Volume of electrolyte solution : $25 \mathrm{ml}$; Weight of resin $=25 \mathrm{mg}$; time : $24 \mathrm{hrs}$ : Room temperature.

$\mathrm{pH}: \mathrm{Fe}(\mathrm{III})=2.5 ; \mathrm{Cu}(\mathrm{II})=4.5 ; \mathrm{Ni}(\mathrm{II})=4.5$; $\mathrm{Co}(\mathrm{II})=5.0 ; \quad \mathrm{Zn}(\mathrm{II})=5.0 ; \quad \mathrm{Cd}(\mathrm{II})=5.0 ; \quad \mathrm{Hg}(\mathrm{II})=$ $6.0 ; \mathrm{Pb}(\mathrm{II})=6.0$

Figure5. Uptake of several metal ions by PTMF copolymer resin at five different concentration of electrolyte solution $\mathrm{NaNO}_{3}$

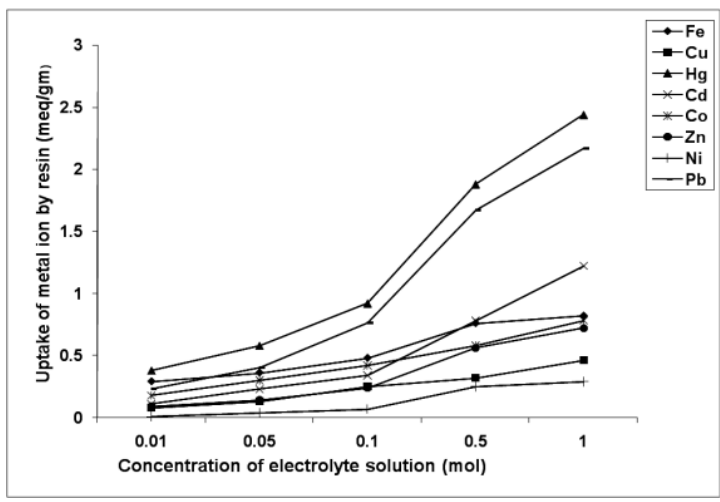

$\left.\mathrm{M}\left(\mathrm{NO}_{3}\right)_{2}\right]=0.1 \mathrm{Mol} / 1 ;$ Volume $=\mathrm{ml}$; Volume of electrolyte solution : $25 \mathrm{ml}$; Weight of resin $=25 \mathrm{mg}$; time : 24 hrs: Room temperature. 
$\mathrm{pH}: \mathrm{Fe}(\mathrm{III})=2.5 ; \quad \mathrm{Cu}(\mathrm{II})=4.5 ; \quad \mathrm{Ni}(\mathrm{II})=4.5 ;$ $\mathrm{Co}(\mathrm{II})=5.0 ; \quad \mathrm{Zn}(\mathrm{II})=5.0 ; \quad \mathrm{Cd}(\mathrm{II})=5.0 ; \quad \mathrm{Hg}(\mathrm{II})=$ 6.0; $\mathrm{Pb}(\mathrm{II})=6.0$

Figure 6. Uptake of several metal ions by PTMF copolymer resin at five different concentration of electrolyte solution $\mathrm{NaCl}$

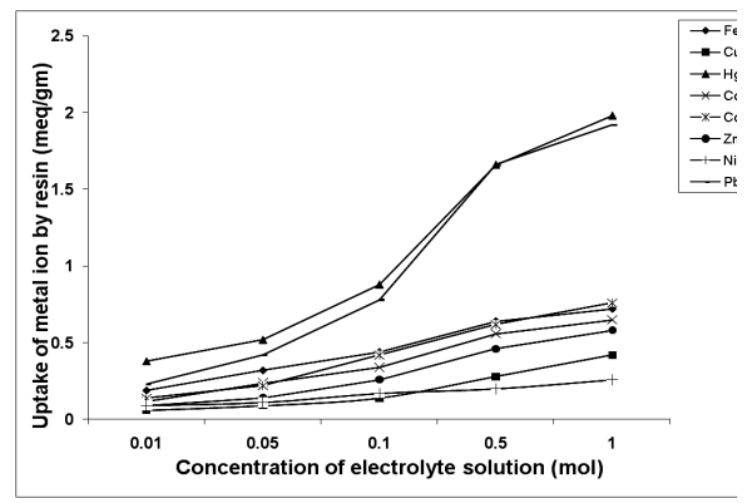

$\left.\mathrm{M}\left(\mathrm{NO}_{3}\right)_{2}\right]=0.1 \mathrm{Mol} / 1$; Volume $=\mathrm{ml}$; Volume of electrolyte solution : $25 \mathrm{ml}$; Weight of resin $=25 \mathrm{mg}$; time : $24 \mathrm{hrs}$ : Room temperature. $\mathrm{pH}: \mathrm{Fe}(\mathrm{III})=2.5 ; \quad \mathrm{Cu}(\mathrm{II})=4.5 ; \quad \mathrm{Ni}(\mathrm{II})=4.5$; $\mathrm{Co}(\mathrm{II})=5.0 ; \quad \mathrm{Zn}(\mathrm{II})=5.0 ; \quad \mathrm{Cd}(\mathrm{II})=5.0 ; \quad \mathrm{Hg}(\mathrm{II})=$ 6.0; $\mathrm{Pb}(\mathrm{II})=6.0$

Figure 7. Uptake of several metal ions by PTMF copolymer resin at five different concentration of electrolyte solution $\mathrm{NaClO}_{4}$

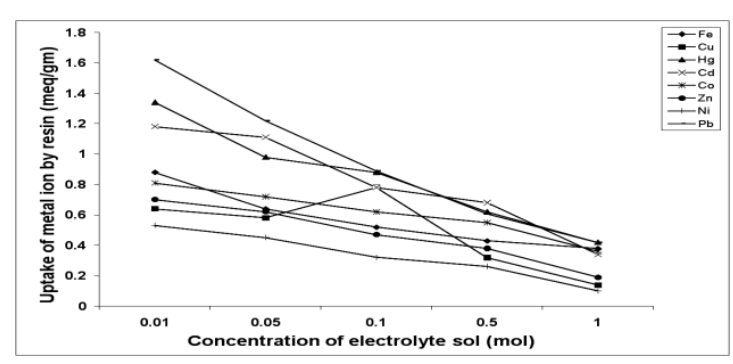

$\left.\mathrm{M}\left(\mathrm{NO}_{3}\right)_{2}\right]=0.1 \mathrm{Mol} / 1$; Volume $=\mathrm{ml}$; Volume of electrolyte solution : $25 \mathrm{ml}$; Weight of resin = $25 \mathrm{mg}$; time : 24 hrs: Room temperature. $\mathrm{pH}: \mathrm{Fe}(\mathrm{III})=2.5 ; \quad \mathrm{Cu}(\mathrm{II})=4.5 ; \quad \mathrm{Ni}(\mathrm{II})=4.5$; $\mathrm{Co}(\mathrm{II})=5.0 ; \quad \mathrm{Zn} \quad(\mathrm{II})=5.0 ; \quad \mathrm{Cd}(\mathrm{II})=5.0 ; \mathrm{Hg}(\mathrm{II})=$ 6.0; $\mathrm{Pb}(\mathrm{II})=6.0$

Figure 8. Uptake of several metal ions by PTMF copolymer resin at five different concentration of electrolyte solution $\mathrm{Na}_{2} \mathrm{SO}_{4}$

\section{Rate of metal ion uptake as a function of time}

The rate of metal adsorption was determined to find out the shortest period of time for which equilibrium could be carried out while operating as close to equilibrium condition as possible. During rate of metal ion determination, the concentration of metal ion and electrolyte solution and $\mathrm{pH}$ of the solution remain constant and $\mathrm{pH}$ of each metal ion is different, which is given in Fig 9. As shaking time increases the polymer gets more time for adsorption, hence uptake of metal ions increases. Figure 9 shows the results of rate of uptake of metal ion on PTMF copolymer resin. The rate refers to the change in the concentration of the metal ions in the aqueous solution which is in contact with the given copolymer. The figure shows that the time taken for the uptake of the different metal ions at a given stage depends on the nature of metal ions under given conditions. It is found that $\mathrm{Fe}^{3+}$ ions required about 3 hrs for the establishment of the equilibrium, whereas $\mathrm{Cu}^{2+}, \mathrm{Zn}^{2+}$ and $\mathrm{Pb}^{2+}$ ions required about 6 hrs. Thus the rate of metal ions uptake follows the order $\mathrm{Fe}^{3+}>\mathrm{Cu}^{2+} \approx \mathrm{Pb}^{2+}>$ $\mathrm{Zn}^{2+}>\mathrm{Ni}^{2+}>\mathrm{Cd}^{2+}>\mathrm{Co}^{2+}$ for the $\mathrm{PTMF}$ copolymer [21].

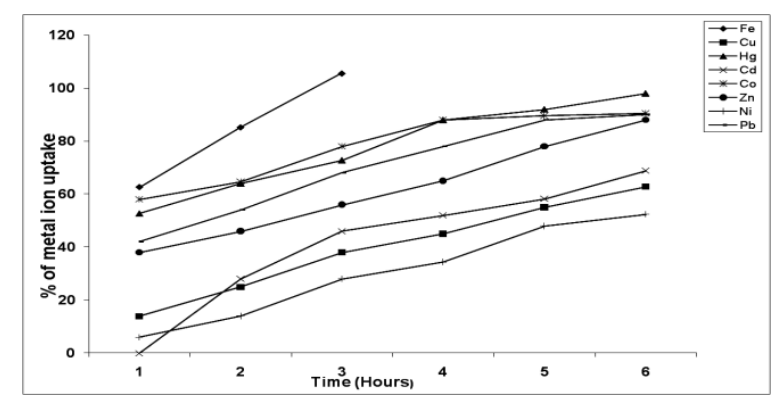

Figure 9 Comparison of the rate of metal ion uptake by PTMF copolymer resin

\section{Distribution ratios of metal ions at different $\mathbf{p H}$}

The distribution of metal ion depends upon $\mathrm{pH}$ of the solution. By increasing $\mathrm{pH}$, the $\mathrm{H}^{+}$ ion concentration in the solution decrease and only metal ion in the solution available 
for adsorption which increase uptake of metal ions.

The effect of $\mathrm{pH}$ on the amount of metal ions distributed between two phases can be explained by the results given in [Fig.10]. The data on the distribution ratio as a function of $\mathrm{pH}$ indicate that the relative amount of metal ions taken up by the copolymers increase with increasing $\mathrm{pH}$ of the medium [22]. The magnitude of increase, however, is different for different metal cations. The study was carried out from 2.5 up to $\mathrm{pH} 6.5$ to prevent hydrolysis of metal ions at higher $\mathrm{pH}$. The selectivity of $\mathrm{Fe}^{3+}$ ion is more for the PTMF copolymer resin as compare to the any other metal ions under study. The order of distribution ratio of metal ions measured in the range, 1.5 to 6.5 is found to be $\mathrm{Fe}^{3+>} \mathrm{Cu}^{2+>} \mathrm{Ni}^{2+>}$ $\mathrm{Zn}^{2+}$ [22]. Thus the results of such type of study are helpful in selecting the optimum $\mathrm{pH}$ for a selective uptake of a particular metal cation from a mixture of different metal ions [23]. For example, the result suggests the optimum $\mathrm{pH} 2.5$ for the separation of $\mathrm{Fe}^{3+}$ and $\mathrm{Zn}^{2+}$ with distribution ratio ' $\mathrm{D}$ ' is 480.2 and 685.7 respectively using the PTMF copolymer resin as ion exchange. Similarly for the separation of $\mathrm{Fe}^{3+}$ at the optimum $\mathrm{pH}$ is 2.5 with distribution ratio is 480.2 for PTMF copolymer. The lowering in the distribution ratios of $\mathrm{Fe}^{3+}$ was found to be small hence, efficient separation could be achieved. The orderof distribution ratio of metal ions measured in $\mathrm{pH}$ range 2.5 to 6.5 is found to be $\mathrm{Fe}^{2+}>\mathrm{Cu}^{2+}>\mathrm{Ni}^{2+} \square \square \mathrm{Cd}^{2+}>\square \mathrm{Zn}^{2+}>\mathrm{Co}^{2+}$ $\square \square \mathrm{Pb}^{2+}$.

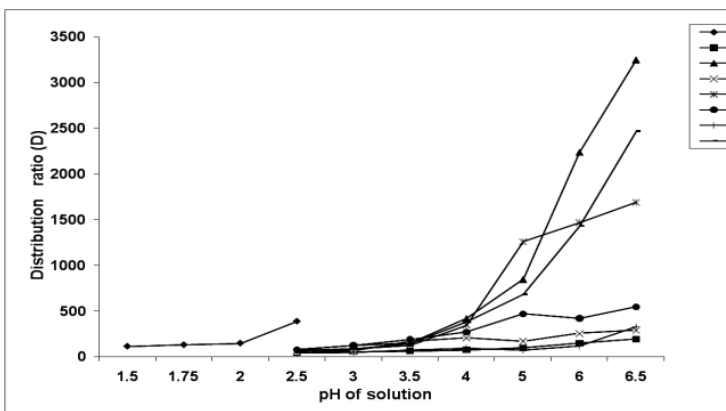

Fig.10. Distribution ration (D) of various metal ions as function of different $\mathrm{pH}$ by by PTMF Copolymer res
Hence, the results of this type of study are helpful in selecting the optimal $\mathrm{pH}$ for a selective uptake of a metal ion from a mixture of different ions. The ion-exchange capacity has been found to be 4.35 mili mol.g-1, which indicates that the copolymer resin is a better ion-exchanger for certain metal ions than some phenolic and polystyrene commercial ion-exchangers.

\section{Conclusions:}

PAMF copolymer resin was prepared from pthallic acid and melamine with formaldehyde in hydrochloric acid medium by condensation technique. The spectral characteristics of the copolymer confirm the linear structure. The semi crystalline amorphous nature of the PAMF copolymer resin was confirmed by SEM studies and reveals that the copolymer can act as an effective ion exchanger for various trivalent and divalent metal ions such as $\mathrm{Fe}^{3+}, \mathrm{Cd}^{2+}$, $\mathrm{Cu}^{2+}, \mathrm{Zn}^{2+}, \mathrm{Ni}^{2+}, \mathrm{Hg}^{2+}$ and $\mathrm{Pb}^{2+}$ ions. This study of ion-exchange reveals that PAMF copolymer resin is an eco-friendly cation exchange resin and can be used for theremoval of hazardous metal ions from the environment, for the purification ofindustrial waste solution and for purification and desalination of water. Thus PAMF copolymer has significant applications as an ion exchange resin in waste water treatment, metal recovery and for the identification of specific metal ions.

\section{Acknowledgments:}

The authors are thankful to STIC, Cochin University, for carrying out the spectral analysis. One of the authors (W.B. Gurnule) thanks the UGC New Delhi for financial assistance.

\section{References:}

Gurnule, W.B., Patle D.B. (2012): Preparation, characterization and chelating Singru, R. N., Gurnule W. B. (2010): Chelating ion-exchange properties of copolymer resins derived from $p$-cresol, oxamide and formaldehyde. Iran Polym Jour. Vol. 19: Pp169-183.

ion-exchange properties of terpolymer resins derived from o-aminophenol, urea and formaldehyde. Elixir Appl Chem. Vol. 50. Pp.10338-10345.

Gurnule, W.B., Charulata M.S., Mudrika A. (2013): Synthesis, characterization, morphology, thermal, electrical and chelation ionexchange properties of a 
copolymer resin. J Environ Res Develop. Vol 7. Pp.1183-1192.

Hydari, S., Sharififard H., Nabavinia, M., Parvizi M.R. (2012): A comparative investigation on removal performances of commercial activated carbon, chitosan biosorbent and chitosan/activated carbon composite for cadmium. ChemEng J. Vol.193-194. Pp.276-282.

Tehrani, M.S., Azar P.A., Namin P.E., Dehaghi S.M. (2013): Removal of lead ions from waste water using functionalized multi-walled carbon nanotubes with tris (2aminoethyl) amine. J Environ Prot. Vol. 4. Pp.529-536.

Bhatt, R.R., Shah B.A., Shah A.V. (2012): Uptake of heavy metal ions by chelating ionexchange resin derived from $p$ hydroxybenzoicacid- formaldehyderesorcinol: synthesis, characterization and sorption dynamics. Malaysian J Anal Sci. Vol. 16. Pp.117-133.

Burkanudeen, A.R., Azarudeen R.S., RiswanAhamed M, Gurnule W.B. (2011): Kinetics of thermal decomposition and antimicrobial screening of terpolymer resins. Polym Bull. Vol. 67. Pp.1553-1568.

Abd El-halim, H.F., Omar M.M., Mohamed G.G. (2011) Synthesis, structural, thermal studies and biological activity of a tridentate Schiff base ligand and their transition metal complexes. SpectrochimActa. Vol. 78. Pp.36-44.

Michael, P.E.P., Barbe J.M., Juneja H.D., Paliwal L.J. (2007) Synthesis, characterization and thermal degradation of 8-hydroxyquinoline-

guanidine-formaldehyde terpolymer. EurPolym J. vol. 43. Pp. 4995-5000.

Azarudeen, R.S., Burkanudeen A.R. (2013): Studies of new oligomer- metal complexes and their antibacterial activities. Polym Int. vol. 62. Pp. 362-374.

Gurnule, W. B., Juneja H. D., Paliwal L. J. (2001):Chelating ion-exchange properties of copolymer resins derived from 8hydroxyquinoline-melamine and formaldehyde. Ultra Sci. vol.13. Pp.333-339. Rahangdale, P. K., Gurnule W.B., Paliwal L. J., Kharat R. B.(2003): Ion-exchange study of 4- hydroxyacetophenon-biuretformaldehyde terpolymer resin, React FunctPolym. Vol. 55. Pp. 255-265.

Mane, V. D., Wahane N. J., Gurnule W. B. (2009):Copolymer resin VII: 8hydroxyquinoline 5 sulphonic acid-thioureaformaldehyde copolymer resin and their ionexchange properties, J Appl Polym Sci. vol. 111. Pp. 3039-3045.
Patel, S. A., Shah B. S and Patel R.M. Patel P. M. (2004): Synthesis, characterization and ion exchange properties of acrylic copolymers derived from 8-quinolinyl methacrylate. Iran Polym Jour. Vol.13 (6). Pp. 445-451.

Patle, D. B. and Gurnule, W. B. (2010): Study of chelation ion-exchange properties of new copolymer resin derived from o-aminophenol, urea and

formaldehyde, Scholars Research Library, Archives of Applied Science

Research. Vol.2 (1). Pp. 261-276.

Rahangdale, S. S. Zade A. B. and Gurnule W. B. (2008): Terpolymer resin

II:Synthesis, characterization, and ionexchange properties of 2, 4-

Dihydroxyacetophenonedithiooxamide-

formaldehyde terpolymers. J.

Appl. Polym. Sci. vol.108(2). Pp.747-756.

Gurnule, W. B. Rahangdale P. K. Paliwal L. J and Kharat R. B. (2003):

Chelation ion-exchange properties of copolymer derived from hydroxyacetophenone, oxamide and formaldehyde, Synth. React. Inorg. Met. Org. Chem. Vol.33(7). Pp. 1187-1194.

Gurnule, W. B. Rahangdale P. K. Paliwal L. J. Kharat R. B. (2002):Ion

exchange properties of 4hydroxyacetophenone-biuret-formaldehyde terpolymer, Prog. Cryst. Grow.Charact. Mat. Vol.45. Pp. 127-130.

Lenka, S., Parija A. and Nayak P. L. (2007):Synthetic resins: XV. Chelation ion exchange properties of 2,4dinitrophenylhydrazone of resacetophenoneformaldehyde resin, Polymer International. Vol.29(2). Pp. 103-106.

Kapadia, M. A., Patel M. M., Patel G. P. and Joshi J. D. (2007): Synthesis, Characterization, and Ion-Exchange Study of Benzophenone Based Resin and Its Polychelates with Lanthanides(III), International Journal of Polymeric Materials. Vol.56(5). Pp. 549-563.

Gurnule, W. B, Rahangdale P. K, Paliwal L. J. and Kharat R. B. (2003): Chelation ion-exchange properties of copolymer resin derived from 4 -hydroxyacetophenone, oxamide, and formaldehyde, J. Appl. Polym. Sci. vol. 89. Pp. 787-780.

Shah, A. B., Shah A. V., Shah M. P. (2006): Synthesis, characterization and Analytical applications of o-substituted benzoic acid chelating resin, Iran Polym J, vol.15. Pp. 809-819.

Cotton, F. A and Wilkinson G. (1972):Advanced Inorganic Chemistry, 3rd ed., Wiley:New York 